\title{
Ion channels or aquaporins as novel molecular targets in gastric cancer
}

\author{
Jianling Xia ${ }^{1,5}$, Hongqiang Wang ${ }^{2,5}$, Shi Li $i^{3}$ Qinghui Wu ${ }^{4}$, Li Sun ${ }^{5}$, Hongxiang Huang ${ }^{5}$ and Ming Zeng ${ }^{1 *}$
}

\begin{abstract}
Gastric cancer (GC) is a common disease with few effective treatment choices and poor prognosis, and has the second-highest mortality rates among all cancers worldwide. Dysregulation and/or malfunction of ion channels or aquaporins (AQPs) are common in various human cancers. Furthermore, ion channels are involved in numerous important aspects of the tumor aggressive phonotype, such as proliferation, cell cycle, apoptosis, motility, migration, and invasion. Indeed, by localizing in the plasma membrane, ion channels or AQPs can sense and respond to extracellular environment changes; thus, they play a crucial role in cell signaling and cancer progression. These findings have expanded a new area of pharmaceutical exploration for various types of cancer, including GC. The involvement of multiple ion channels, such as voltage-gated potassium and sodium channels, intracellular chloride channels, 'transient receptor potential' channels, and AQPs, which have been shown to facilitate the pathogenesis of other tumors, also plays a role in GC. In this review, an overview of ion channel and aquaporin expression and function in carcinogenesis of GC is presented. Studies of ion channels or AQPs will advance our understanding of the molecular genesis of GC and may identify novel and effective targets for the clinical application of GC.
\end{abstract}

Keywords: Ion channels, Potassium, Chloride, Calcium, Sodium, Aquaporin, Gastric cancer, Therapeutic target

\section{Background}

Gastric cancer (GC) remains as a highly lethal malignancy worldwide, particular for developing country, which makes it a key public health problem [1-3]. High incidence regions include Asia, Eastern Europe and Middle and South America [4]. Complete remission of early GC by surgical or even minimal invasion endoscopic resection removal is now possible as a result of developments in therapeutic techniques [5]. Nevertheless, the majority of GC patients are asymptomatic only until entering an advanced stage. Common therapeutic options include surgery, radiotherapy, and chemotherapy $[6,7]$. Studies have shown that patients with advanced stage GC have a poor prognosis with a 5-year survival rate less than 30\% [8]. Recently, advances in the biology and molecular profiling of GC have resulted in targeted treatments and better survival rates in select patients with advanced GC. Trastuzumab and ramucirumab are two

\footnotetext{
* Correspondence: miller2002@yahoo.com

${ }^{1}$ Cancer Center, Sichuan Academy of Medical Sciences and Sichuan

Provincial People's Hospital, Hospital of the University of Electronic Science

and Technology of China, The Western First Round Road, Section 2\#32,

Chengdu 610072, China

Full list of author information is available at the end of the article
}

new therapeutic targeted drugs that have been approved in the last 5 years for the treatment of advanced GC [9]. However, the development of more highly effective and selective targeted agents is still an important issue for the appropriate management of advanced GC and more research is needed to further improve outcome.

Ion channels and aquaporins (AQPs) are comprised of transmembrane proteins that regulate the permeation of specific ions or water between the extracellular and intracellular environments. Ion channels or AQPs form rapid cell signals in excitatory tissues by modifying ion fluxes at various sites within cells on various time scales. Ion channels and AQPs also contributed to slower processes, such as volume regulation, proliferation, apoptosis, migration, invasion and cell adhesion in nonexcitable cells [10-14]. It has become increasingly clear over the last 15 years that splicing, dysregulated expression and/or function of ion channels and/or AQPs exists in many types of cancers and this leads to multiple cancer processes (Figs. 1 and 2). In addition, ion channels and AQPs may modulate cell activities and control many key aspects of neoplastic progression. They may also determine the fate of these cells. Therefore, ion channels 


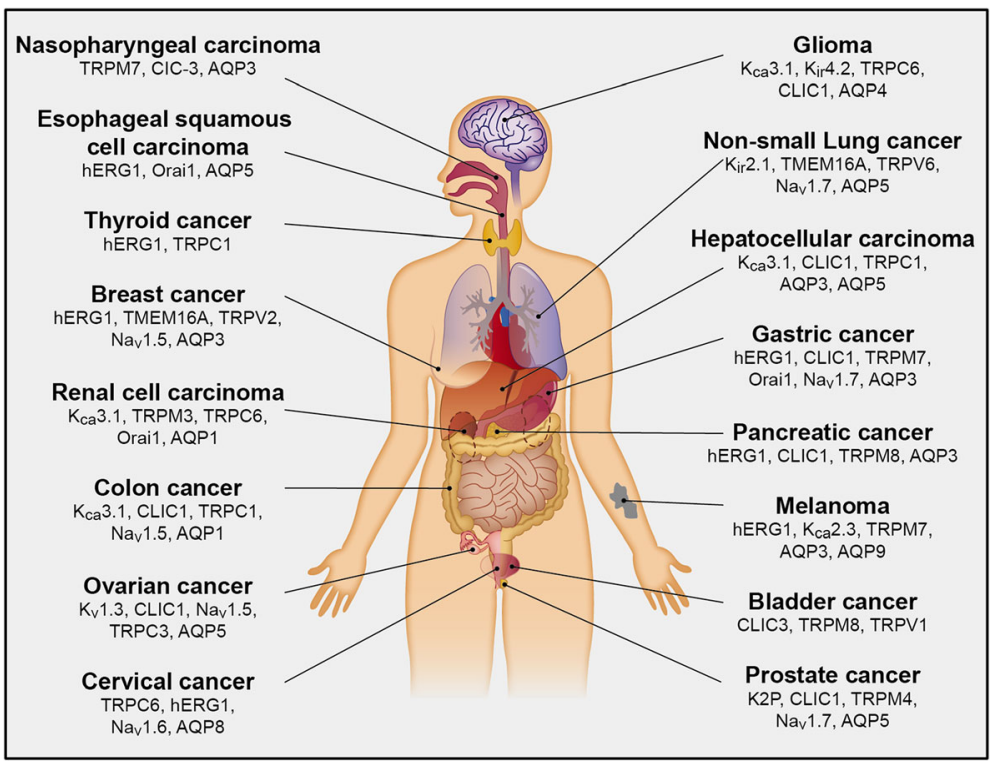

Fig. 1 Representative ion channels or aquaporins associated with malignant behavior of tumor cells

that have an impact on cancer development and/or progression are called "oncogenic channels" [15]. Many studies from different laboratories have shown that adjustment of ion channels or AQPs by either altered expression or inhibited activity can weaken the growth and/or migration of cancer cells. This means ion channels or AQPs could become pharmaceutic targets in GC management [16].

The primary aim of this review was to provide an update of recent advances on the role of ion channels and AQPs in GC. The final objective was to assess the potential use of ion channels in the clinical management of $\mathrm{GC}$ and to evaluate the possibility of ion channels to be pharmacological targets for GC.

\section{Potassium channels}

Potassium $\left(\mathrm{K}^{+}\right)$channels have the greatest amount of diversity among ion channels and aquaporin in the plasma

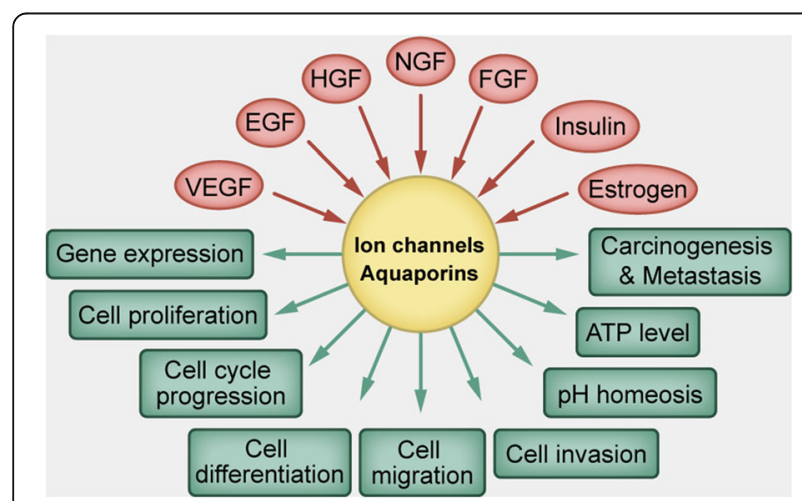

Fig. 2 Multiple characteristics of ion channels and aquaporins under different stimuli and showing different responses membrane, which are encoded by over 75 distinct genes. There are four main classes according to their activation mechanisms and domain structure. They are: calciumactivated $\mathrm{K}^{+}$channels $\left(\mathrm{K}_{\mathrm{Ca}}\right)$, voltage-gated $\mathrm{K}^{+}$channels $\left(\mathrm{K}_{\mathrm{v}}\right)$, inward-rectifier $\mathrm{K}^{+}$channels $\left(\mathrm{K}_{\mathrm{ir}}\right)$ and two-poredomain $\mathrm{K}^{+}$channels (K2P). The voltage-dependent $\mathrm{K}^{+}$ channel $\left(\mathrm{K}_{\mathrm{v}}\right)$ family can be subdivided into $\mathrm{K}_{\mathrm{v}} 1-4$ channels (Shaker, Shab, Shaw and Shal-like subunits), the silent $\mathrm{K}_{\mathrm{v}} 5, \mathrm{~K}_{\mathrm{v}} 6, \mathrm{~K}_{\mathrm{v}} 8$ and $\mathrm{K}_{\mathrm{v}} 9$ subunits (regulators), $\mathrm{K}_{\mathrm{v}} 7$ channels (KCNQ), and $\mathrm{K}_{\mathrm{v}} 10-12$ channels (EAG-like) $[17,18]$. Potassium channels in non-excitable cells are likely involved in mediating intracellular $\mathrm{Ca}^{2+}$ concentrations, cell volume, $\mathrm{pH}$ homeosis, apoptosis, cell cycle and differentiation [19]. Many studies have shown that ectopic expression of $\mathrm{K}^{+}$channels occurs in human cancers. There are four main classes of $\mathrm{K}^{+}$channels that have been involved in oncological processes [20]. As an example, intermediate-conductance calcium-activated potassium (SK4) channels have been identified to overexpress in triple-negative breast cancer. They are also implicated in proliferation, apoptosis, migration and epithelial-to-mesenchymal transition (EMT) processes of cancer cells [21]. $\mathrm{K}_{\mathrm{ir}} 2.1$ regulates tumor cell proliferation and drug resistance by modulation of multidrug resistance protein 1 (MRP1). It is also simultaneously regulated by miR-7 and the Ras/mitogen-activated protein kinase (MAPK) pathway in small-cell lung cancer [22]. Meanwhile, it has been shown that TREK-1, which is in the K2P family, is overexpressed in prostate cancer. High levels of TREK- 1 were positively related to T staging and Gleason scores. They were also associated with shorter castration resistance free survival. In addition, TREK-1 
knockdown significantly attenuated prostate cancer cell proliferation both in vitro and in vivo. Also, TREK-1 induced a G1/S cell cycle arrest [23]. $K_{\mathrm{v}} 9.3$ in colon cancer showed similar results [24].

Various $\mathrm{K}^{+}$channels have been shown to play an important role in GC progression, particularly the human enter a go-go related potassium channel (hERG1), which is also known as $\mathrm{K}_{\mathrm{v}} 11.1$ and belongs to the EAG family. hERG1 has been demonstrated to be negatively expressed in the surrounding non-cancerous tissues; however, this switched to abnormally positive expression in GC tissues according to immunohistochemistry analysis. This indicated that hERG1 is a potential biomarker for GC [25]. hERG1 expression levels have also been correlated with TNM stage, grading, lymph node involvement, tumor differentiation and vascular endothelial growth factor (VEGF)-A expression. hERG1 has also been shown to enhance GC cell invasion and proliferation, induce cell cycle progression in vitro, and promote tumor genesis and growth in vivo. Furthermore, hERG1 modulates VEGF-1 secretion through an AKTdependent pathway [26, 27]. Of significance, hERG1 has been demonstrated to be necessary for cisplatin induction of apoptosis in GC and may provide a new potential target for cisplatin chemotherapy [28]. In addition to hERG1 participating in GC cell behavior, other $\mathrm{K}^{+}$channels are also crucial in GC. Kir2.2 knockdown results in senescence-induced mitochondrial dysfunction. This dysfunction includes increases in the mitochondrial mass and reactive oxygen species (ROS) production, as well as decreases in the mitochondrial membrane potential and ATP levels in GC [29]. Also, $K_{\mathrm{v}} 4.1$ was demonstrated to affect cell cycle distribution and facilitate cell proliferation [30]. $\mathrm{K}_{\mathrm{Ca}}$ (the detailed subtype is not known) is possibly involved in hepatocyte growth factor (HGF)-induced GC cell proliferation [31]. Similarly, KCNQ1 and $K_{\mathrm{v}} 1.5$ were identified to be involved in GC progression $[32,33]$. There have not been any reports, however, on the role of $\mathrm{K} 2 \mathrm{P}$ in $\mathrm{GC}$.

In summary, different $\mathrm{K}^{+}$channels can remarkably affect various aspects of GC cell behaviors both in vitro and in vivo. Therefore, the clinical potential of $\mathrm{K}^{+}$channels should be studied further, especially regarding underlying cell signaling pathways.

\section{Chloride channels}

In a study by Jentsch et al., chloride $\left(\mathrm{Cl}^{-}\right)$channels were divided into 6 categories based on the opening mechanisms of the channels: 1 ) the cystic fibrosis transmembrane conductance regulator (CFTR), which is a cAMPactivated $\mathrm{Cl}^{-}$channel, 2) voltage-gated $\mathrm{Cl}^{-}$channels (ClCs), which are gated in a voltage-reliant manner, 3) $\mathrm{Ca}^{2+}$-activated $\mathrm{Cl}^{-}$channels (CACCs), which are dependent on intracellular calcium, 4) volume-regulated
$\mathrm{Cl}^{-}$channels (VRACs), which are also called swellingactivated $\mathrm{Cl}^{-}$channels, 5) a family of p64-related proteins (CLICs), which are putative intracellular $\mathrm{Cl}^{-}$ channels, and (6) $\gamma$-aminobutyric acid and glycine receptors, which are ligand-gated $\mathrm{Cl}^{-}$channels. The primary functions of $\mathrm{Cl}^{-}$channels are regulation of trans-epithelial transport, volume (osmoregulation), membrane potentials and cellular immune responses [34]. They were shown to be critical for tumor progression in several studies. C1C3 has been proposed to promote cervical cancer cell membrane ruffling, which is required for tumor metastasis and may be a valuable prognostic biomarker and therapeutic target [35]. Studies on nasopharyngeal carcinoma cells showed similar results [36]. Meanwhile, $\mathrm{Ca}^{2+}$-activated $\mathrm{Cl}^{-}$ channel transmembrane protein 16A (TMEM16A, also known as ANO1) could promote breast cancer progression by activating calmodulin-dependent protein kinase (CAMK) and epidermal growth factor receptor (EGFR) signaling [37]. It may also act on cell invasion and proliferation, and tumor growth in non-small cell lung cancer [38]. In colon and pancreatic cancer, it seems that CLIC1 may be a putative oncogene and may play a pivotal role in tumor progression $[39,40]$.

In $\mathrm{GC}$, intracellular $\mathrm{Cl}^{-}$has been suggested to regulate lysosomal acidification and autophagy functions, which indicated an important role of $\mathrm{Cl}^{-}$in $\mathrm{GC}$ progression [41]. CLIC1 has been shown to be involved in GC development and, importantly, CLIC1 was considered to be a possible prognostic marker for GC. Its expression levels in GC samples were increased relative to adjacent noncancerous mucosa, and were associated with the TNM stage, perineural invasion, lymph node metastasis and a 5-year survival rate [42]. In addition, elevated CLIC1 expression was implicated to accelerate the invasion and migration of GC cells in vitro. This is possibly mediated by proteasome activator $28 \beta$ subunit (PA28 $\beta$ ), which then affects the ROS-mediated p38 MAPK signaling pathway [43, 44]. However, it is intriguing that high CLIC1 expression could also enhance apoptosis and inhibit proliferation [45]. There is also evidence that TMEM16A was involved in GC progression. TMEM16A was significantly amplified and upregulated in GC specimens. The overexpression of TMEM16A was positively associated with disease stage and negatively associated with patient survival, identifying it as an independent prognostic factor for patient outcome [46]. The upregulation of TMEM16A could be due to the transcriptional factor and activator of transcription 6 (STAT6) binding to its promoter region in response to IL-4 [47]. Few studies, however, have investigated how TMEM16A modulated downstream activity.

In conclusion, the involvement of CLIC1 and TMEM16A channels in GC cell migration, invasion and disease progression has been demonstrated. Nevertheless, more studies are 
required to determine whether other $\mathrm{Cl}^{-}$channels play a role in GC progression. Also, studies are needed to increase knowledge of the mechanistic side of $\mathrm{Cl}^{-}$channel pathophysiology and in vivo experiments should be performed.

\section{Calcium channels}

The "transient receptor potential" (TRP) channels include a wide variety of ion channels. The majority are permeable to divalent and monovalent cations and they influence calcium $\left(\mathrm{Ca}^{2+}\right)$ homeostasis. There are seven subfamilies of TRP channels that comprise the vanilloid receptor related (TRPV), classical (TRPC), and melastatin-related (TRPM) channels $[48,49]$. These channels play an important role in the cell cycle, which often occurs by regulating gene transcription. Also, these channels influence other cellular processes such as apoptosis, proliferation and cell motility [50]. An increasing number of reports have shown TRP channels are involved in tumor progression. In breast cancer, high levels of TRPM7 have been confirmed to independently predict poor outcomes and TRPM7 is functionally required for metastasis in a mouse xenograft model. In terms of mechanisms, TRPM7 regulates myosin II-based cellular tension. This then regulates the focal adhesion number, polarized cell movement and cell-cell adhesion [51]. Meanwhile, TRPV2 was higher in prostate cancer with metastatic cancer (stage M1) relative to primary solid tumors (stages T2a and T2b). TRPV2 has been demonstrated to facilitate the growth of prostate cancer cells and their invasive properties. It also upregulated expression of invasive enzymes such as matrix metalloproteinase-2 (MMP2), MMP9 and cathepsin B in vitro and in nude mice [52]. Furthermore, TRPC6 was shown to be essential for glioma development through modulation of G2/M phase transition. It therefore could be a new target for glioma therapeutic intervention [53].

Store operated $\mathrm{Ca}^{2+}$ entry (SOCE), which is constituted by pore forming $\mathrm{Ca}^{2+}$ channel subunits Orai1, Orai2 and/or Orai3, and also their modulators STIM1 and/or STIM2, is critical for $\mathrm{Ca}^{2+}$ oscillation, except for the TRP channels that have been implicated in $\mathrm{Ca}^{2+}$ homeostasis in cells [54]. Orail and STIM1 have been shown to be highly expressed in tumor cells, and may contribute to malignant biological behaviors. For example, Orai1/STIM1 expression and/or function are elevated in therapy resistant ovary carcinoma cells, which is at least in part due to increased AKT activity. Also, this may influence therapy resistance in these cells [55]. In addition, Orai1 and STIM1 are crucial for breast cancer cell migration in vitro and tumor metastasis in vivo [56].

In GC, TRPM7 plays an influential role in the growth and survival of GC cells. It can also depress cell apoptosis and is likely to be a potential target for pharmacological therapy of GC [57, 58]. TRPV6 mediates capsaicin-induced apoptosis in GC cells. The abundance of TRPV6 in GC cells determines life or death after capsaicin treatment [59]. The TRPC6 channels are essential for $\mathrm{GC}$ cell proliferation and the $\mathrm{G} 2 / \mathrm{M}$ phase transition in vitro, and also for the development of GC in nude mice [60]. Moreover, we showed that intracellular $\mathrm{Ca}^{2+}$ is elevated in GC cells. Also, store-operated $\mathrm{Ca}^{2+}$ currents are found in GC cells. The composite molecules of SOCE; i.e., Orai1 and STIM1 suggest a poor outcome for GC by advancing tumor cell proliferation, metabolism, migration, and invasion through targeting metastasisassociated in colon cancer-1 (MACC1) [61].

In summary, the data suggest that upregulation of certain subtypes of $\mathrm{Ca}^{2+}$ channels contribute to $\mathrm{GC}$ tumorigenesis, progression and, possibly, drug resistance. $\mathrm{Ca}^{2+}$ channels are therefore potential drug targets for GC.

\section{Voltage-gated sodium channels}

Voltage-gated sodium $\left(\mathrm{Na}^{+}\right)$channels (VGSCs) consist of a pore-forming $\alpha$ subunit, typically crosslinking with one or more, identical or different, smaller $\beta$ subunits [62]. Nine genes in humans (SCN1A to SCN5A, and SCN8A to SCN11A) code for nine distinct VGSC proteins $\left(\mathrm{Na}_{\mathrm{v}} 1.1\right.$ to $\mathrm{Na}_{\mathrm{v}} 1.9$, respectively) associated with differences in their $\alpha$ subunits [63]. These proteins allow voltage-dependent activation of sodium current, and are also responsible for membrane depolarization, which is thought to be specific in cells characterized as being "excitable", such as skeletal cells, cardiac muscle cells and neurons [64]. Over the last 15 years, an increasing number of studies have shown the expression of these channels in non-excitable cells. In these cells, they affect physiological functions such as endocytosis, phagocytosis, secretion, motility, and cell proliferation and differentiation [65-68]. There has been a rapid expansion of published studies documenting the expression of VGSCs in many cancers. Also, their role in the regulation of cellular invasion and migration and, importantly, their potential use as diagnostic and/or therapeutic targets has also been studied [69]. In colon cancer, $\mathrm{Na}_{\mathrm{v}} 1.5$ is overexpressed and is a vital controller of a gene transcriptional system that regulates cell invasion [70]. In non-small cell lung cancer, $\mathrm{Na}_{\mathrm{v}} 17$ is required for the epidermal growth factor (EGF)-mediated extracellular signal-regulated kinase $1 / 2(E R K 1 / 2)$ pathway to enhance cell invasion [71]. Likewise, in cervical cancer, overexpressed $\mathrm{Na}_{\mathrm{v}} 1.6$ has been correlated with increased tumor cell invasion [72].

In $\mathrm{GC}$, our results indicated that $\mathrm{Na}_{\mathrm{v}} 1.7$ was the most abundantly expressed VGSC subtype in both GC tissues and GC cell lines. $\mathrm{Na}_{\mathrm{v}} 1.7$ expression was shown to be frequently higher in GC tissues compared to non-malignant samples. $\mathrm{Na}_{\mathrm{v}} 1.7$ expression was correlated to $\mathrm{GC}$ patient prognosis and also with the transporter $\mathrm{Na}^{+} / \mathrm{H}^{+}$ exchanger-1 (NHE1) and the oncoprotein MACC1 
expression. Inhibition of $\mathrm{Na}_{\mathrm{v}} 1.7$ led to reduced NHE1 expression. This ultimately resulted in a slower rate of GC cells invasion and proliferation in vitro and tumor growth in nude mice. $\mathrm{Na}_{\mathrm{v}} 1.7$ suppression was also associated with decreased expression of MACC1, and MACC1 suppression resulted in decreased NHE1 expression. The study results demonstrated that $\mathrm{Na}_{\mathrm{v}} 1.7$ controls GC cell invasion and proliferation by MACC1-mediated upregulation of NHE1. Therapies that specifically target $\mathrm{Na}_{\mathrm{v}} 1.7$ might successfully impede GC progression [73]. However, there have been no other reports on VGSCs in GC.

In summary, despite that our data suggested that functional $\mathrm{Na}_{\mathrm{v}} 1.7$ expression have broad influence on the pathophysiology of $\mathrm{GC}$, the available evidence remains limited. Further studies on both the basic and clinical aspects are needed. Also, these studies should extend to other intracellular mechanisms and assess whether $\mathrm{Na}_{\mathrm{v}} 1.7$ is related to drug resistance.

\section{AQPs}

AQPs are part of a special superfamily of membrane integral proteins, which are known as major intrinsic proteins. AQPs can transport water and sometimes water and glycerol ("aquaglyceroporins"). They therefore can regulate cell volumes and can regulate body water homeostasis $[74,75]$. AQP0 to AQP12 of this family were reported. They were divided into three subgroups based on their main sequences: water selective (AQP0, 1, 2, 4, 5, 6, and 8 ), aquaglyceroporins (AQP3, 7, 9, and 10), and superaquaporins (AQP11 and 12) [76]. AQPs have been shown to be crucial for malignancy. AQP3, for example, induced ERK1/2 activation. This then increases MMP-3 expression and secretion, and therefore controls prostate cancer cell invasion and motility [77]. AQP4 has been implicated to be upregulated in glioma specimens and plays a critical role in glioma-associated edema [78]. AQP5 has been shown to be overexpressed in breast cancer and it possibly acts on cell proliferation and migration [79]. In addition, AQP8 has been shown to be involved in cervical cancer progression [80].

GC tissues express obviously higher levels of AQP3 compared to normal gastric mucosa. Also, upregulation of AQP3 was related to EMT-associated proteins and may predict poor outcome for GC. AQP3 regulated GC cell proliferation, invasion and migration. It also can induce an alteration in expression levels of EMT-related proteins and MMPs through the PI3K/AKT/SNAIL signaling pathway in vitro [81]. In addition, AQP3 can transport glycerol, which is required for GC cell energy production and lipid synthesis [82]. As for its upstream, a study reported that $c$-Met could modulate AQP3 expression through the ERK1/2 signaling pathway in GC [83]. Moreover, miR-874 suppresses AQP3 expression by binding to the 3'UTR of AQP3 mRNA in GC cells [84].
Also, human EGF induced AQP3 expression in a timeand dose-dependent manner in GC cells [85]. An additional AQP subtype that has been demonstrated to play a role in malignant biological behaviors of GC cells is AQP5. The overexpression of AQP5 was observed in $\mathrm{GC}$ tissues relative to the paired normal tissues, according to a study by Huang et al. This upregulation was correlated with enhanced lymph node metastasis according to immunohistochemistry. In vitro, overexpression of AQP5 significantly promoted, while knockdown of AQP5 notably inhibited the capacity of GC cell proliferation and migration [86]. Also, AQP5 upregulation may play a role in GC cell differentiation [87]. These results indicated that modulation of AQP5 expression or function may be a potential treatment for GC even though the detailed mechanisms by which AQP5 promotes GC progression is unknown.

In conclusion, there is a possibility that AQP channels have clinical potential for the treatment of $\mathrm{GC}$, as is the case with other cancers. Yet, further studies are needed to reveal other subtypes of AQP channels that participate in tumor progression and provide insight into the pathophysiological aspects of GC more deeply. Also, more in vivo experiments are required to support the above-mentioned findings.

\section{Pharmacological targeting of ion channels and AQPs for cancer therapy}

The above paragraphs have shown the crucial role of ion channels and AQPs in tumor progression. Thus, using specific pharmacological modulators of ion channels or AQPs may pave the way for novel cancer therapy. For example, treatment with margatoxin (MgTX), which is a selective inhibitor of $\mathrm{K}_{\mathrm{v}} 1.3$, or short hairpin RNA against $\mathrm{K}_{\mathrm{v}} 1.3$, notably attenuated non-small cell lung cancer cell proliferation and altered cell cycle progression. The use of MgTX in a lung adenocarcinoma model for 7 days obviously lessened tumor volume by $75 \%$. Injection of MgTX into the tumor tissues of nude mice significantly increased p21 expression level and significantly decreased cycline D3 and CDK4 expression levels, indicating this blocker controls the cell cycle at G1-S in vivo, which was similar to the in vitro cultured system [88]. Likewise, as an antagonist of TRPM8, cannabigerol (CBG) inhibited cell proliferation, induced cell apoptosis and stimulated ROS production in colon cancer cells. In an in vivo study, nude mice were subcutaneously injected with colon cancers cells. CBG (3 mg/kg or $10 \mathrm{mg} / \mathrm{kg}$ given intraperitoneally every day) used as treatment produced a dramatic reduction from day 3 of treatment to the end of the experiment [89]. Also, the VGSC-blocking drug phenytoin suppressed the invasion and migration of breast cancer cells in vitro. Phenytoin treatment also significantly reduced cancer cell invasion 
into the surrounding mammary tissue and tumor growth in vivo. Phenytoin significantly inhibited metastasis to the lungs, liver and spleen [90]. In addition, a decrease in CLIC1-mediated $\mathrm{Cl}^{-}$currents and glioblastoma cell proliferation were also seen with CLIC1 antibody addition. Meanwhile, glioblastoma cells exposed toisotype control antibodies or CLIC1 antibodies were transplanted into the brains of immunodeficient mice. CLIC1 antibody treatment led to smaller tumors and significantly improved overall survival in mice. This indicated treatment with CLIC1 antibodies produces an obvious decrease in in vivo tumorigenicity of glioblastoma cells [91].

There are a number of inhibitors of AQPs that may be useful in treating tumors other than the above- mentioned inhibitors of ion channels (the structure of some inhibitors of AQPs are shown in Fig. 3) [92-94]. In colon cancer, for example, inhibition of AQP1 by AqB013 effectively reduced tumor cell migration and invasion as well as endothelial tube formation [95]. In pancreatic cancer, inhibition of AQP3 by the inhibitor $\mathrm{CuSO} 4$ attenuated tumor cell migration, which suggested it was a potential therapeutic treatment agent for pancreatic cancer [96]. Meanwhile, there are a few patents that have been filed that represent small molecule AQP modulators and pharmaceutical formulations, such as WO2013005170 (metal-based inhibitor of aquaglyceroporins AQP3, AQP7, and AQP9), US8835491 (modulator of orthodox aquaporin AQP1), and WO2008052190<smiles>C=CCCCNc1cc(Oc2ccccc2)c(S(=O)(=O)O)cc1C(=O)O</smiles>
Bumetamide<smiles>[Y]c1c(C([2H])=O)cc(S(=O)(=O)N([R9])C)c([X])c1[Y]</smiles><smiles>[Y]c1ncc(S(=O)(=O)N([R8])C)cc1C([B])=O</smiles>

$\mathrm{B}=-\mathrm{OH},-\mathrm{OR},-\mathrm{OCHR}, \mathrm{OCOR}_{2},-\mathrm{NR}_{1} \mathrm{R}_{2}$

$X, Y, Z=-H$, -halogen, $-\mathrm{OH},-\mathrm{OR},-\mathrm{NHR},-\mathrm{NHCOR},-\mathrm{NHSO}_{2} \mathrm{R},-\mathrm{SOR}, \mathrm{SO}_{2} \mathrm{R}$ $\mathrm{R}=$ linear or branched alkyl, aryl or aryl $\mathrm{C} 1$ to $\mathrm{C} 6$ alkyl, heteroaryl etc.

$\mathrm{R} 1, \mathrm{R} 2=-\mathrm{H}$, linear or branched C1-C6 alkyl, etc.

$\mathrm{W}=\mathrm{S}, \mathrm{O}, \mathrm{NR}(\mathrm{R}=\mathrm{H}$, alkyl, aryl alkyl)

B<smiles>[X]c1ccc([Z])c(S(=O)(=O)N([R6])[R])c1</smiles><smiles>[R]Oc1ccc([R1])cc1C(=O)Nc1cc([R3])c([R])c([R])c1[R]</smiles><smiles>[R3]c1ccc(OP([R5])([R])=O)c(C(=O)Nc2cc([R3])c([R3])c([R3])c2[R2])c1</smiles>

C
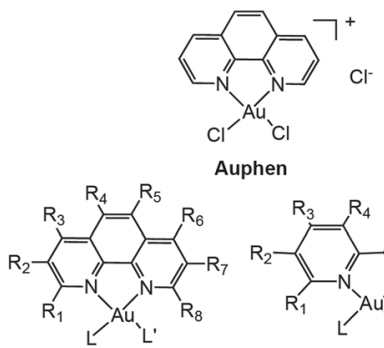

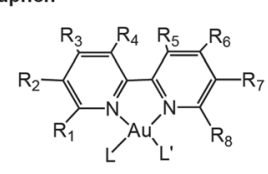

$\mathrm{R}=\mathrm{H}$, amine, halogen, alkyl, aryl, carboxy, alkoxy etc. $\mathrm{L}, \mathrm{L}^{\prime}=$ halogen, $\mathrm{OH}, \mathrm{CH}_{3} \mathrm{COO}^{-}$,etc

$\mathrm{Z}=\mathrm{a}$ cyclic moiety selected from the group consisting of homocyclic and heterocyclic aromaticl aliphatic moieties

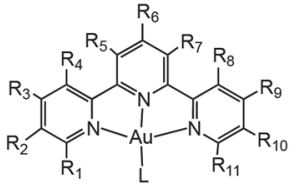

Fig. 3 The structures of some aquaporin inhibitors are shown. a Structure of sulfonamide-based compounds that act as AQP1 and AP4 modulators. b Structure of AQP2 and AQP4 phenylbenzamide-type inhibitors and associated pro-drug salts. c Gold(III) complexes that can be selective aquaglyceroporin inhibitors 
(modulators of orthodox aquaporin AQP4) that may be used in therapeutic applications in the clinic [92].

As illustrated in the above examples of other types of cancer, this relatively new area of study has already led to the identification of potential therapeutic drugs for GC. With the use of hERG1 inhibitor E4031 daily for 2 weeks starting from the day after inoculum in in vivo experiments, the masses were notably decreased with E4031 treatment, which was paralleled by the decrease in tumor angiogenesis. In addition, within the masses in E4031treated mice, there was a reduction in VEGF-A expression and AKT prosphoralation, which strongly confirmed the in vitro data [26]. SKF96365, an agent known to block TRPC channels, also stagnated the GC cell cycle in the G2/M phase and inhibited cell proliferation in vitro. Application of SKF96365 (20 mg/kg) for 5 successive days through intraperitoneal injection after 7-day implantation led to reduced tumor volume in vivo [60]. Our study showed the VGSC inhibitor tetrodotoxin (TTX) decreased MACC1 and NHE1 expressions, which decreased the extracellular $\mathrm{pH}$ and increased the intracellular $\mathrm{pH}$. This affected the GC cell proliferation and invasion in vitro [73]. However, we did not use TTX in the experiments on mice, which should be done in the future.

Since the set of ion channels that promote GC development is now known, it is imperative to conduct indepth research on the specific ion-channel targeting drugs. Furthermore, the potential side-effects should be addressed.

\section{Conclusions and future perspectives Conclusions}

The primary conclusions of this review are the following: 1) many ion channels and AQPs are differentially expressed in GC tissues and cells relative to normal gastric mucosal specimens and cells. 2) Changes in the expression or activity of ion channels or AQPs give the GC cells a pathological character and the ion channels then affect various aspects of the malignant behavior of GC cells, such as proliferation, migration and invasion. 3) Multiple signaling pathways may be activated by ion channels and AQPs and this could enhance a variety of oncogenes, thereby contributing to $\mathrm{GC}$ tumorigenesis and progression. 4) Inhibiting the expression or blocking the activity of ion channels or AQPs impairs GC cell function both in vitro and in vivo, which could open a new avenue for pharmaceutical research in GC. We therefore suggest that ion channels could be realistic, functional biomarkers and new therapeutic targets in $\mathrm{GC}$, as in many other cancers.

\section{Future perspectives}

Much more work needs to be done on GC from multiple aspects. Firstly, the ion channels or AQPs that have already received attention require further characterization. Moreover, other ion channels or AQPs that might be possibly important are worth investigation. Secondly, angiogenesis, lymphangiogenesis, autophagy dysregulation, and the Warburg effect are ubiquitous in GC, and these phenomena are regulated by ion channels and/or AQPs in many other types of cancer. Therefore, whether ion channels and/or AQPs affect the above-mentioned phenomena in GC should also be determined. Crociani et al. showed that HERG1 regulated VEGF-A expression and angiogenesis in GC and a combined treatment with hERG1 inhibitors and antiangiogenic drugs could enhance the therapeutic effect and repress tumor growth [26]. Dong et al. demonstrated that AQP3 promotes cisplatin resistance in GC cells through autophagy [97]. There have been no additional reports, however, about the relationship between ion channels/AQPs and the other abovementioned phenomena in the progression of GC. Thirdly, the detailed mechanisms or other factors that are involved in GC processes should be explored further even though some signaling pathways or oncogenes have been confirmed to participate in the contribution of ion channels to $\mathrm{GC}$ progression. In addition, ion channels or AQPs may be regulated by growth factors such as EGF, HGF, VEGF, nerve growth factor (NGF) and fibroblast growth factor (FGF), as well as the hormones estrogen and insulin [30, 71, 98-102] (Fig. 2). However, the research on the upstream of the ion channels or AQPs is still limited, which attenuates our understanding of how the ion channels or AQPs are upregulated and/or activated. Fourth, albeit many previous reports showed circumstantial evidence, there is a conspicuous insufficiency of studies that have utilized site-directed mutagenesis to change the biophysical properties of the related currents. Meanwhile, KO mouse models may also assist with establishing the facility of these interesting proteins, which is absent in the present studies. Finally, and importantly, specific blockers or antagonists that specifically act on certain subtypes of ion channels or AQPs and have few side effects should be developed to translate basic research findings into clinical applications. The currently available agents primarily influence a variety of ion channel or aquaporin subtypes; however, these agents are not specific, which can lead to clinically adverse effects that limit their usage. Thus, there is an urgent need to develop drugs that target specific subtypes of ion channels or AQPs. Furthermore, large-scale studies should evaluate whether these agents have protective function over the long-term in GC patients.

In summary, the use of ion channels or AQPs as diagnostic, prognostic, or therapeutic targets for GC is possible. $\mathrm{K}^{+}$channels (hERG1, Kir2.2, $\mathrm{K}_{\mathrm{v}} 4.1, \mathrm{KCNQ} 1$, and $\left.\mathrm{K}_{\mathrm{v}} 1.5\right), \mathrm{Cl}^{-}$channels (CLIC1, and TMEM16A), $\mathrm{Ca}^{2+}$ channels (TRPM7, TRPV6, TRPC6, and Orai1), $\mathrm{Na}^{+}$ channels $\left(\mathrm{Na}_{\mathrm{v}} 1.7\right)$, and AQPs (AQP3, and AQP5) may be 
potential candidate markers for GC. Further research and rigorous evaluation are needed to determine which is better for use in the clinic. Although progress has been made in this area, much work remains to be conducted. Furthermore, the exploration of pharmacological agents for ion channels may enable the development of therapies for GC.

\section{Abbreviations \\ AQP: Aquaporin; CBG: Cannabigerol; EGF: Epidermal growth factor; EMT: Epithelial-to-mesenchymal transition; ERK1/2: Extracellular signal-regulated kinase 1/2; FGF: Fibroblast growth factor; GC: Gastric cancer; HGF: Hepatocyte growth factor; MACC1: Metastasis-associated in colon cancer-1; MAPK: Mitogen- activated protein kinase; MgTX: Margatoxin; MMPs: Matrix metalloproteinases; NGF: Nerve growth factor; NHE1: $\mathrm{Na}^{+} / \mathrm{H}^{+}$exchanger-1; ROS: Reactive oxygen species; SOCE: The store operated $\mathrm{Ca}^{2+}$ entry; TRP channels: 'Transient receptor potential' channels; TTX: Tetrodotoxin; VEGF: Vascular endothelial growth factor; VGSCs: Voltage-gated sodium channels}

\section{Acknowledgements}

The authors thank the members of M. Zeng's laboratory for advice and discussions.

\section{Funding}

This work was financially supported by the National Key Research and Development Program of China (no. 2016YFC0105107) and the National Natural Science Foundation of China (no. 81502116).

\section{Availability of data and materials}

Not applicable.

\section{Authors' contributions}

MZ designed the outline of the paper. JLX, SL and LS wrote the manuscript. $\mathrm{HQW}, \mathrm{QHW}$ and $\mathrm{HXH}$ prepared the figures. All authors have read and approved the final version of this manuscript.

\section{Competing interests}

The authors declare that they have no competing interests.

\section{Consent for publication}

Not applicable

\section{Ethics approval and consent to participate}

Not applicable.

\section{Author details \\ 'Cancer Center, Sichuan Academy of Medical Sciences and Sichuan Provincial People's Hospital, Hospital of the University of Electronic Science and Technology of China, The Western First Round Road, Section 2\#32, Chengdu 610072, China. ²Department of Oncology, Zhoushan Hospital, Zhoushan 316000, China. ${ }^{3}$ Department of Urology, The First Affiliated Hospital of Wenzhou Medical University, Wenzhou 325015, China. ${ }^{4}$ Department of Urology, Hainan Provincial People's Hospital, Haikou 570311, China. ${ }^{5}$ Department of Oncology, Nanfang Hospital, Southern Medical University, Guangzhou 510515, China.}

Received: 19 November 2016 Accepted: 22 February 2017 Published online: 06 March 2017

\section{References}

1. Siegel R, Ma J, Zou Z, Jemal A. Cancer statistics. CA Cancer J Clin. 2014;64:9-29.

2. Jemal A, Bray F, Center MM, Ferlay J, Ward E, Forman D. Global cancer statistics. CA Cancer J Clin. 2011;61:69-90.

3. Ferlay J, Soerjomataram I, Dikshit R, Eser S, Mathers C, Rebelo M, et al. Cancer incidence and mortality worldwide: sources, methods and major patterns in GLOBOCAN 2012. Int J Cancer. 2015;136(5):E359-86.

4. Arnold M, Moore SP, Hassler S, Ellison-Loschmann L, Forman D, Bray F. The burden of stomach cancer in indigenous populations: a systematic review and global assessment. Gut. 2014;63:64-71.
5. Mihmanli M, Ilhan E, Idiz UO, Alemdar A, Demir U. Recent developments and innovations in gastric cancer. World J Gastroenterol. 2016;22:4307-20.

6. Riquelme I, Tapia O, Leal P, Sandoval A, Varga MG, Letelier P, et al. miR-101-2, miR125b-2 and miR-451a act as potential tumor suppressors in gastric cancer through regulation of the PI3K/AKT/mTOR pathway. Cell Oncol (Dordr). 2016;39:23-33.

7. Lim SM, Lim JY, Cho JY. Targeted therapy in gastric cancer: personalizing cancer treatment based on patient genome. World J Gastroenterol. 2014;20:2042-50.

8. Ferlay J, Soerjomataram I, Ervik M, Dikshit R, et al. GLOBOCAN 2012 v1.0, Cancer incidence and mortality worldwide: IARC CancerBase No. 11. 2012 [cited 2016 January 25]. http://globocan. iarc.fr.

9. Jou E, Rajdev L. Current and emerging therapies in unresectable and recurrent gastric cancer. World J Gastroenterol. 2016;22:4812-23.

10. Hoffmann EK, Holm NB, Lambert IH. Functions of volume-sensitive and calcium-activated chloride channels. IUBMB Life. 2014;66:257-67.

11. Lang F, Ritter M, Völkl H, Häussinger D. The biological significance of cell volume. Ren Physiol Biochem. 1993;16:48-65.

12. Kondratskyi A, Kondratska K, Skryma R, Prevarskaya N. Ion channels in the regulation of apoptosis. Biochim Biophys Acta. 1848;2015:2532-46.

13. Schwab A, Stock C. Ion channels and transporters in tumour cell migration and invasion. Philos Trans R Soc Lond B Biol Sci. 2014;369:20130102.

14. Litan A, Langhans SA. Cancer as a channelopathy: ion channels and pumps in tumor development and progression. Front Cell Neurosci. 2015;9:86.

15. Pedersen SF, Stock C. Ion channels and transporters in cancer: pathophysiology, regulation, and clinical potential. Cancer Res. 2013;73:1658-61.

16. Munaron L, Arcangeli A. Editorial: ion fluxes and cancer. Recent Pat Anticancer Drug Discov. 2013;8:1-3.

17. Hille B. Ion Channels of Excitable Membranes. 3rd ed. Sunderland, Mass: Sinauer; 2001.

18. McCrossan ZA, Abbott GW. The MinK-related peptides. Neuropharmacology. 2004:47:787-821.

19. Niemeyer BA, Mery L, Zawar C, Suckow A, Monje F, Pardo LA, et al. Ion channels in health and disease. 83rd Boehringer Ingelheim Fonds International Titisee Conference. EMBO Rep. 2001;2:568-73.

20. Huang X, Jan LY. Targeting potassium channels in cancer. J Cell Biol. 2014 206:151-62

21. Zhang P, Yang X, Yin Q, Yi J, Shen W, Zhao L, et al. Inhibition of SK4 potassium channels suppresses cell proliferation, migration and the epithelial-mesenchymal transition in triple-negative breast cancer cells. PLoS One. 2016;11:e0154471.

22. Liu H, Huang J, Peng J, Wu X, Zhang Y, Zhu W, et al. Upregulation of the inwardly rectifying potassium channel Kir2.1 (KCNJ2) modulates multidrug resistance of small-cell lung cancer under the regulation of miR-7 and the Ras/MAPK pathway. Mol Cancer. 2015;14:59.

23. Zhang GM, Wan FN, Qin XJ, Cao DL, Zhang HL, Zhu Y, et al. Prognostic significance of the TREK-1 K2P potassium channels in prostate cancer. Oncotarget. 2015;6:18460-8.

24. Lee JH, Park JW, Byun JK, Kim HK, Ryu PD, Lee SY, et al. Silencing of voltagegated potassium channel Kv9.3 inhibits proliferation in human colon and lung carcinoma cells. Oncotarget. 2015;6:8132-43.

25. Ding XW, Yang WB, Gao S, Wang W, Li Z, Hu WM, et al. Prognostic significance of hERG1 expression in gastric cancer. Dig Dis Sci. 2010;55:1004-10.

26. Crociani O, Lastraioli E, Boni L, Pillozzi S, Romoli MR, D’Amico M, et al. hERG1 channels regulate VEGF-A secretion in human gastric cancer: clinicopathological correlations and therapeutical implications. Clin Cancer Res. 2014;20:1502-12.

27. Shao XD, Wu KC, Guo XZ, Xie MJ, Zhang J, Fan DM. Expression and significance of HERG protein in gastric cancer. Cancer Biol Ther. 2008;7:45-50.

28. Zhang R, Tian P, Chi Q, Wang J, Wang Y, Sun L, et al. Human ether-à-go-gorelated gene expression is essential for cisplatin to induce apoptosis in human gastric cancer. Oncol Rep. 2012;27:433-40

29. Lee I, Park C, Kang WK. Knockdown of inwardly rectifying potassium channel Kir2.2 suppresses tumorigenesis by inducing reactive oxygen species-mediated cellular senescence. Mol Cancer Ther. 2010;9:2951-9.

30. Kim HJ, Jang SH, Jeong YA, Ryu PD, Kim DY, Lee SY. Involvement of Kv4.1 K(+) channels in gastric cancer cell proliferation. Biol Pharm Bull. 2010;33:1754-7.

31. Liu SI, Chi CW, Lui WY, Mok KT, Wu CW, Wu SN. Correlation of hepatocyte growth factor-induced proliferation and calcium-activated potassium current in human gastric cancer cells. Biochim Biophys Acta. 1998:1368:256-66.

32. Zhang J, Zhao Z, Zu C, Hu H, Shen H, Zhang M, et al. Atrial natriuretic peptide modulates the proliferation of human gastric cancer cells via KCNQ1 expression. Oncol Lett. 2013;6:407-14. 
33. Bielanska J, Hernández-Losa J, Pérez-Verdaguer M, Moline T, Somoza R, Ramón Y, Cajal S, et al. Voltage-dependent potassium channels Kv1.3 and Kv1.5 in human cancer. Curr Cancer Drug Targets. 2009;9:904-14.

34. Jentsch TJ, Stein V, Weinreich F, Zdebik AA. Molecular Structure and Physiological Function of Chloride Channels. Physiol Rev. 2002;82:503-68.

35. Xu B, Jin X, Min L, Li Q, Deng L, Wu H, et al. Chloride channel-3 promotes tumor metastasis by regulating membrane ruffling and is associated with poor survival. Oncotarget. 2015;6:2434-50.

36. Yang $L$, Ye D, Ye W, Jiao C, Zhu L, Mao J, et al. ClC-3 is a main component of background chloride channels activated under isotonic conditions by autocrine ATP in nasopharyngeal carcinoma cells. J Cell Physiol. 2011;226:2516-26.

37. Britschgi A, Bill A, Brinkhaus H, Rothwell C, Clay I, Duss S, et al. Calcium-activated chloride channel ANO1 promotes breast cancer progression by activating EGFR and CAMK signaling. Proc Natl Acad Sci U S A. 2013;110:E1026-34.

38. Jia L, Liu W, Guan L, Lu M, Wang K. Inhibition of calcium-activated chloride channel ANO1/TMEM16A suppresses tumor growth and invasion in human lung cancer. PLoS One. 2015;10:e0136584.

39. Wang P, Zeng Y, Liu T, Zhang C, Yu PW, Hao YX, et al. Chloride intracellular channel 1 regulates colon cancer cell migration and invasion through ROS/ ERK pathway. World J Gastroenterol. 2014;20:2071-8.

40. Lu J, Dong Q, Zhang B, Wang X, Ye B, Zhang F, et al. Chloride intracellular channel 1 (CLIC1) is activated and functions as an oncogene in pancreatic cancer. Med Oncol. 2015;32:616.

41. Hosogi S, Kusuzaki K, Inui T, Wang X, Marunaka Y. Cytosolic chloride ion is a key factor in lysosomal acidification and function of autophagy in human gastric cancer cell. J Cell Mol Med. 2014;18:1124-33.

42. Chen CD, Wang CS, Huang YH, Chien KY, Liang Y, Chen WJ, et al. Overexpression of CLIC1 in human gastric carcinoma and its clinicopathological significance. Proteomics. 2007;7:155-67.

43. Zheng DL, Huang QL, Zhou F, Huang QJ, Lin JY, Lin X. PA28ß regulates cell invasion of gastric cancer via modulating the expression of chloride intracellular channel. J Cell Biochem. 2012;113:1537-46.

44. Zhao W, Lu M, Zhang Q. Chloride intracellular channel 1 regulates migration and invasion in gastric cancer by triggering the ROS-mediated p38 MAPK signaling pathway. Mol Med Rep. 2015;12:8041-7.

45. Ma PF, Chen JQ, Wang Z, Liu JL, Li BP. Function of chloride intracellular channel 1 in gastric cancer cells. World J Gastroenterol. 2012;18:3070-80.

46. Liu F, Cao QH, Lu DJ, Luo B, Lu XF, Luo RC, et al. TMEM16A overexpression contributes to tumor invasion and poor prognosis of human gastric cancer through TGF- $\beta$ signaling. Oncotarget. 2015;6:11585-99.

47. Mazzone A, Gibbons SJ, Bernard CE, Nowsheen S, Middha S, Almada LL, et al. Identification and characterization of a novel promoter for the human ANO1 gene regulated by the transcription factor signal transducer and activator of transcription 6 (STAT6). FASEB J. 2015;29:152-63.

48. Owsianik G, D'hoedt D, Voets T, Nilius B. Structure-function relationship of the TRP channel superfamily. Rev Physiol Biochem Pharmacol. 2006;156:61-90.

49. Nilius B, Owsianik G, Voets T, Peters JA. Transient receptor potential cation channels in disease. Physiol Rev. 2007;87:165-217.

50. Shapovalov G, Ritaine A, Skryma R, Prevarskaya N. Role of TRP ion channels in cancer and tumorigenesis. Semin Immunopathol. 2016;38:357-69.

51. Middelbeek J, Kuipers AJ, Henneman L, Visser D, Eidhof I, van Horssen R, et al. TRPM7 is required for breast tumor cell metastasis. Cancer Res. 2012;72:4250-61.

52. Monet M, Lehen'kyi V, Gackiere F, Firlej V, Vandenberghe M, Roudbaraki M, et al. Role of cationic channel TRPV2 in promoting prostate cancer migration and progression to androgen resistance. Cancer Res. 2010;70:1225-35.

53. Ding X, He Z, Zhou K, Cheng J, Yao H, Lu D, et al. Essential role of TRPC6 channels in G2/M phase transition and development of human glioma. J Natl Cancer Inst. 2010;102:1052-68.

54. Bhardwaj R, Hediger MA, Demaurex N. Redox modulation of STIM-ORAI signaling. Cell Calcium. 2016.

55. Schmidt S, Liu G, Liu G, Yang W, Honisch S, Pantelakos S, et al. Enhanced Orai1 and STIM1 expression as well as store operated Ca2+ entry in therapy resistant ovary carcinoma cells. Oncotarget. 2014;5:4799-810.

56. Yang S, Zhang JJ, Huang XY. Orai1 and STIM1 are critical for breast tumor cell migration and metastasis. Cancer Cell. 2009;15:124-34.

57. Kim BJ, Kim SY, Lee S, Jeon JH, Matsui H, Kwon YK, et al. The role of transient receptor potential channel blockers in human gastric cancer cell viability. Can J Physiol Pharmacol. 2012;90:175-86.

58. Kim BJ, Park EJ, Lee JH, Jeon JH, Kim SJ, So I. Suppression of transient receptor potential melastatin 7 channel induces cell death in gastric cancer. Cancer Sci. 2008;99:2502-9.
59. Chow J, Norng M, Zhang J, Chai J. TRPV6 mediates capsaicin-induced apoptosis in gastric cancer cells-Mechanisms behind a possible new "hot"cancer treatment. Biochim Biophys Acta. 2007;1773:565-76.

60. Cai R, Ding X, Zhou K, Shi Y, Ge R, Ren G, et al. Blockade of TRPC6 channels induced $\mathrm{G} 2 / \mathrm{M}$ phase arrest and suppressed growth in human gastric cancer cells. Int J Cancer. 2009;125:2281-7.

61. Xia J, Wang H, Huang H, Sun L, Dong S, Huang N, Shi M, et al. Elevated Orai1 and STIM1 expressions upregulate MACC1 expression to promote tumor cell proliferation, metabolism, migration, and invasion in human gastric cancer. Cancer Lett. 2016;381:31-40.

62. Catterall WA. Cellular and molecular biology of voltage-gated sodium channels. Physiol Rev. 1992;72:S15-48.

63. Catterall WA. From ionic currents to molecular mechanisms: the structure and function of voltage-gated sodium channels. Neuron. 2000;26:13-25.

64. Roger S, Gillet L, Le Guennec JY, Besson P. Voltage-gated sodium channels and cancer: is excitability their primary role? Front Pharmacol. 2015;6:152.

65. Black JA, Newcombe J, Waxman SG. Nav1.5 sodium channels in macrophages in multiple sclerosis lesions. Mult Scler. 2013;19:532-42.

66. Brackenbury WJ, Djamgoz MB, Isom LL. An emerging role for voltage-gated $\mathrm{Na}+$ channels in cellular migration: Regulation of central nervous system development and potentiation of invasive cancers. Neuroscientist. 2008;14:571-83.

67. Andrikopoulos P, Fraser SP, Patterson L, Ahmad Z, Burcu H, Ottaviani D, et al. Angiogenic functions of voltage-gated $\mathrm{Na}+$ channels in human endothelial cells: modulation of vascular endothelial growth factor (VEGF) signaling. J Biol Chem. 2011;286:16846-60.

68. Chatelier A, Mercier A, Tremblier B, Thériault O, Moubarak M, Benamer N, et al. A distinct de novo expression of Nav1.5 sodium channels in human atrial fibroblasts differentiated into myofibroblasts. J Physiol. 2012;590:4307-19.

69. Brackenbury WJ. Voltage-gated sodium channels and metastatic disease. Channels (Austin). 2012;6:352-61.

70. House CD, Vaske CJ, Schwartz AM, Obias V, Frank B, Luu T, et al. Voltagegated $\mathrm{Na}+$ channel SCN5A is a key regulator of a gene transcriptional network that controls colon cancer invasion. Cancer Res. 2010;70:6957-67.

71. Campbell TM, Main MJ, Fitzgerald EM. Functional expression of the voltagegated $\mathrm{Na}(+)$-channel Nav1.7 is necessary for EGF-mediated invasion in human non-small cell lung cancer cells. J Cell Sci. 2013;126:4939-49.

72. Hernandez-Plata E, Ortiz CS, Marquina-Castillo B, Medina-Martinez I, Alfaro A, Berumen J, et al. Overexpression of NaV 1.6 channels is associated with the invasion capacity of human cervical cancer. Int J Cancer. 2012;130:2013-23.

73. Xia J, Huang N, Huang H, Sun L, Dong S, Su J, et al. Voltage-gated sodium channel Nav1.7 promotes gastric cancer progression through MACC1mediated upregulation of NHE1. Int J Cancer. 2016;139:2553-69.

74. Agre P. The aquaporin water channels. Proc Am Thorac Soc. 2006;3:5-13.

75. Magni F, Sarto C, Ticozzi D, Soldi M, Bosso N, Mocarelli P, et al. Proteomic knowledge of human aquaporins. Proteomics. 2006;6:5637-49.

76. Verkman AS. Aquaporins at a glance. J Cell Sci. 2011;124:2107-12.

77. Chen J, Wang Z, Xu D, Liu Y, Gao Y. Aquaporin 3 promotes prostate cancer cell motility and invasion via extracellular signal-regulated kinase 1/2-mediated matrix metalloproteinase-3 secretion. Mol Med Rep. 2015;11:2882-8.

78. Yang L, Wang X, Zhen S, Zhang S, Kang D, Lin Z. Aquaporin-4 upregulated expression in glioma tissue is a reaction to glioma-associated edema induced by vascular endothelial growth factor. Oncol Rep. 2012;28:1633-8.

79. Jung HJ, Park JY, Jeon HS, Kwon TH. Aquaporin-5: a marker protein for proliferation and migration of human breast cancer cells. PLoS One. 2011;6:e28492.

80. Shi YH, Rehemu N, Ma H, Tuokan T, Chen R, Suzuke L. Increased migration and local invasion potential of SiHa cervical cancer cells expressing Aquaporin 8. Asian Pac J Cancer Prev. 2013;14:1825-8.

81. Chen J, Wang T, Zhou YC, Gao F, Zhang ZH, Xu H, et al. Aquaporin 3 promotes epithelial-mesenchymal transition in gastric cancer. J Exp Clin Cancer Res. 2014;33:38.

82. Li Z, Li B, Zhang L, Chen L, Sun G, Zhang Q, et al. The proliferation impairment induced by AQP3 deficiency is the result of glycerol uptake and metabolism inhibition in gastric cancer cells. Tumour Biol. 2016;37:9169-79.

83. Wang J, Gui Z, Deng L, Sun M, Guo R, Zhang W, et al. c-Met upregulates aquaporin 3 expression in human gastric carcinoma cells via the ERK signalling pathway. Cancer Lett. 2012;319:109-17.

84. Jiang B, Li Z, Zhang W, Wang H, Zhi X, Feng J, et al. miR-874 Inhibits cell proliferation, migration and invasion through targeting aquaporin-3 in gastric cancer. J Gastroenterol. 2014;49:1011-25.

85. Huang Y, Zhu Z, Sun M, Wang J, Guo R, Shen L, et al. Critical role of aquaporin-3 in the human epidermal growth factor-induced migration and 
proliferation in the human gastric adenocarcinoma cells. Cancer Biol Ther. 2010:9:1000-7.

86. Huang YH, Zhou XY, Wang HM, Xu H, Chen J, Lv NH. Aquaporin 5 promotes the proliferation and migration of human gastric carcinoma cells. Tumour Biol. 2013;34:1743-51.

87. Watanabe T, Fujii T, Oya T, Horikawa N, Tabuchi Y, Takahashi Y, et al. Involvement of aquaporin-5 in differentiation of human gastric cancer cells. J Physiol Sci. 2009;59:113-22.

88. Jang SH, Choi SY, Ryu PD, Lee SY. Anti-proliferative effect of Kv1.3 blockers in A549 human lung adenocarcinoma in vitro and in vivo. Eur J Pharmacol. 2011;651:26-32

89. Borrelli F, Pagano E, Romano B, Panzera S, Maiello F, Coppola D, et al. Colon carcinogenesis is inhibited by the TRPM8 antagonist cannabigerol, a Cannabisderived non-psychotropic cannabinoid. Carcinogenesis. 2014;35:2787-97.

90. Nelson M, Yang M, Dowle AA, Thomas JR, Brackenbury WJ. The sodium channel-blocking antiepileptic drug phenytoin inhibits breast tumour growth and metastasis. Mol Cancer. 2015;14:13.

91. Setti M, Savalli N, Osti D, Richichi C, Angelini M, Brescia P, et al. Functional role of CLIC1 ion channel in glioblastoma-derived stem/progenitor cells. J Natl Cancer Inst. 2013;105:1644-55.

92. Soveral G, Casini A. Aquaporin modulators: a patent review (2010-2015). Expert Opin Ther Pat. 2017;27:49-62.

93. de Almeida A, Soveral G, Casini A. Gold compounds as aquaporin inhibitors: new opportunities for therapy and imaging. Med Chem Commun. 2014;5:1444-53.

94. Chulso M, David M. Aquaporins in health and disease: new molecular targets for drug discovery. In: Graca S, Soren N, Angela C, editors. Aquaporins in carcinogenesis: water and glycerol channels as new potential drug targets. Boca Raton: CRC Press; 2015. p. 217-32.

95. Dorward HS, Du A, Bruhn MA, Wrin J, Pei JV, Evdokiou A, et al. Pharmacological blockade of aquaporin-1 water channel by AqB013 restricts migration and invasiveness of colon cancer cells and prevents endothelial tube formation in vitro. J Exp Clin Cancer Res. 2016;35:36.

96. Liu W, Wang K, Gong K, Li X, Luo K. Epidermal growth factor enhances MPC-83 pancreatic cancer cell migration through the upregulation of aquaporin 3. Mol Med Rep. 2012;6:607-10.

97. Dong $X$, Wang $Y$, Zhou Y, Wen J, Wang S, Shen L. Aquaporin 3 facilitates chemoresistance in gastric cancer cells to cisplatin via autophagy. Cell Death Discov. 2016;2:16087.

98. Ge R, Tai Y, Sun Y, Zhou K, Yang S, Cheng T, et al. Critical role of TRPC6 channels in VEGF-mediated angiogenesis. Cancer Lett. 2009;283:43-51.

99. Brackenbury WJ, Djamgoz MBA. Nerve growth factor enhances voltagegated $\mathrm{Na}+$ channel activity and transwell migration in Mat-LyLu rat prostate cancer cell line. J Cell Physiol. 2007;210:602-8.

100. Kessler W, Budde T, Gekle M, Fabian A, Schwab A. Activation of cell migration with fibroblast growth factor-2 requires calcium-sensitive potassium channels. Pflugers Arch. 2008:456:813-23.

101. Chodon D, Guilbert A, Dhennin-Duthille I, Gautier M, Telliez MS, Sevestre H, et al. Estrogen regulation of TRPM8 expression in breast cancer cells. BMC Cancer. 2010;10:212.

102. Lilja J, Laulund F, Forsby A. Insulin and insulin-like growth factor type-I upregulate the vanilloid receptor-1 (TRPV1) in stably TRPV1-expressing SH-SY5Y neuroblastoma cells. J Neurosci Res. 2007;85:1413-9.

\section{Submit your next manuscript to BioMed Central and we will help you at every step:}

- We accept pre-submission inquiries

- Our selector tool helps you to find the most relevant journal

- We provide round the clock customer support

- Convenient online submission

- Thorough peer review

- Inclusion in PubMed and all major indexing services

- Maximum visibility for your research

Submit your manuscript at www.biomedcentral.com/submit

) Biomed Central 